\title{
Width of dental arches in patients with maxillary midline diastema
}

\author{
A. Sękowska ${ }^{1}$, R. Chałas ${ }^{2}$, I. Dunin-Wilczyńska ${ }^{1}$ \\ ${ }^{1}$ Department of Jaw Orthopaedics, Medical University of Lublin, Poland \\ ${ }^{2}$ Department of Conservative Dentistry and Endodontics, Medical University of Lublin, Poland
}

[Received: 10 August 2017; Accepted: 2 October 2017]

Background: The aims of the study were as follows: (1) to examine the width of the dental arches of patients with maxillary midline diastema and compare it with control group; (2) to investigate the impact of the width of upper dental arch on the width of diastema.

Materials and methods: Diagnostic orthodontic plaster models of 102 patients with permanent dentition were studied. Patients were divided into two groups: study group with diastema and control group without diastema. Patients with severe malocclusion, craniofacial diseases, hypodontia and microdontia and patients with periodontal disease were excluded. The transpalatal width of palate, premolar and molar arch widths in Pont's points of upper and lower jaw were measured using digital calliper. The results were statistically analysed.

Results: Analysis showed a significant correlation between presence of diastema and premolar and molar width of the dental arches for both upper and lower jaw. Studied widths were larger in patients with diastema compared to the group without diastema. Analysis of the transpalatal width showed statistically significant differences between the study group and the control group. Analysis of widths of diastema and transpalatal widths showed that there was not statistically significant correlation.

Conclusions: Patients with diastema had increased in size in both the premolar and molar width of the dental arches. Increase the width affect to both upper and lower dental arch. Patients with diastema also were characterised by often occurrence of normal or increased of the transpalatal width but the width of the diastema did not correlate with the width of the palate. (Folia Morphol 2018; 77, 2: 340-344)

Key words: Pont's points, Pont's width, transpalatal width

\section{INTRODUCTION}

Spaces between teeth are called diastemata. Maxillary midline diastema between upper central incisors is the most popular diastema but diastemata between other teeth are also observed [19]. Prevalence of diastemata in adults is between 3.7\% [27] and 36.8\% [21].

There are many causes of diastema. Four general groups of diastema causes are described [2]: (1) Den- tal defects, for example, microdontia or hypodontia of teeth especially in upper lateral incisors $[4,26]$ or supernumerary teeth between upper central incisors especially mesiodens [4, 15, 28]; (2) Periodontal defect, such as improper frenulum attachment $[3,4,8$, 12] or periodontal disease $[6,12,13]$; (3) Muscular defect such as large tongue [10, 14]; (4) Neuromuscular defect - improper position of tongue during

Address for correspondence: R. Chałas, MD, PhD, Department of Conservative Dentistry and Endodontics, Medical University of Lublin, ul. Karmelicka 7, 20-081 Lublin, Poland, tel: +48 81528 7920, e-mail: renata.chalas@umlub.pl 
rest or function like swallowing or speech. Still another cause of diastema is dento-alveolar discrepancy, which means that not only teeth could be too small but also dental arches could be too large [12, 20, 24, 25].

There are many points described in literature and used to measure the width of dental arches [17]. One of the most popular is Pont's points [7]. In 1909 Pont established Pont's Index to predict maxillary dental arch width basing on the sum of the mesio-distal widths of the four maxillary incisors. Measure points were established for premolar and molar widths and for upper (Fig. 1) and lower arch (Fig. 2). In normal occlusion premolar and molar points in upper and lower arch should coincide. The analysis helps to determine if the dental arch is narrow or normal and if the expansion is necessary or not [22].

Other points for measuring transpalatal arch width were described by McNamara (Fig. 3). The transpalatal width between the first upper molar measured from the closest points between the lingual surfaces should be equal to $36-38 \mathrm{~mm}$ for the permanent dentition and $34-36 \mathrm{~mm}$ for the mixed dentition [18].

There are two main aims of the study. The first aim is to compare the width of dental arches between two groups of patients with upper midline diastema and without diastema. The second aim is to investigate the impact of the width of upper dental arch on the diastema width.

\section{MATERIALS AND METHODS}

This study was approved by Bioethics Committee of the Medical University of Lublin (No. KE0254/29/2014). Diagnostic orthodontic plaster models of 102 Caucasian race patients were studied. All patients had permanent dentition (DS4M2) according to Björk, that means Dental Stage 4 - fully erupted canines and premolars and $\mathrm{M} 2$ - fully erupted second molars [5]. Patients were divided into two groups: with diastema $(n=50)$ and control group without diastema $(n=52)$. Both groups were similar according to age and sex. Mean age in the patient group was $24.00 \pm 6.26$ years and in the control group $22.45 \pm$ \pm 5.28 years. The females accounted for the most part of both groups $(78.8 \%$ in the study group and $86 \%$ in the control group). Occlusion status was also similar in both groups. The Angle's class I was dominant in patients $(96.2 \%$ in diastema group and $76 \%$ in control

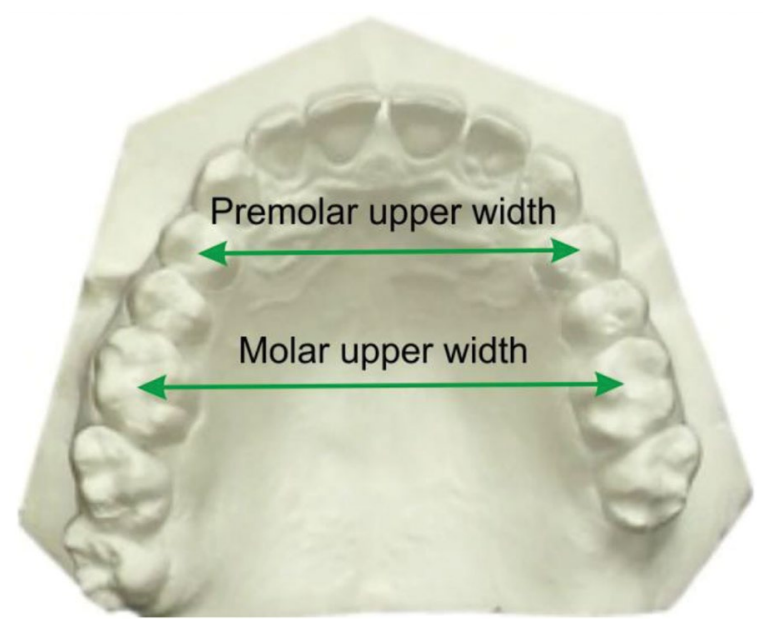

Figure 1. Pont's points and widths in upper dental arch.

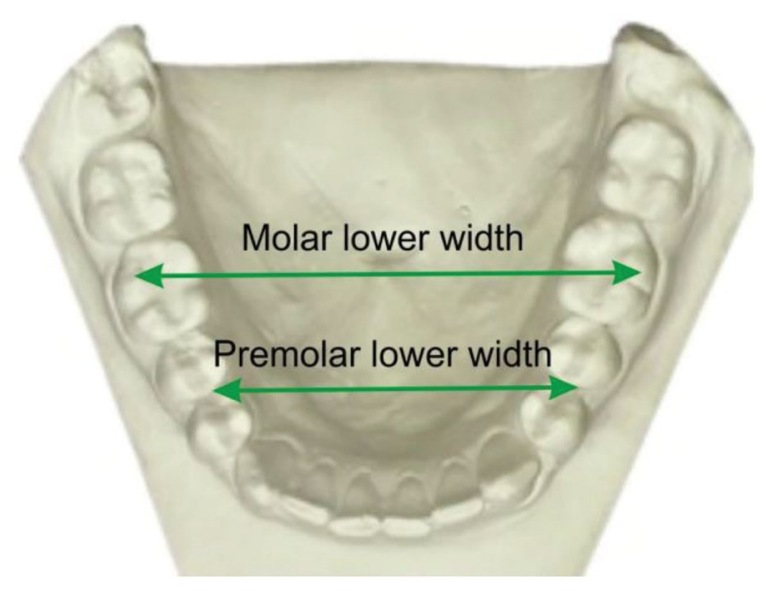

Figure 2. Pont's points and widths in lower dental arch.

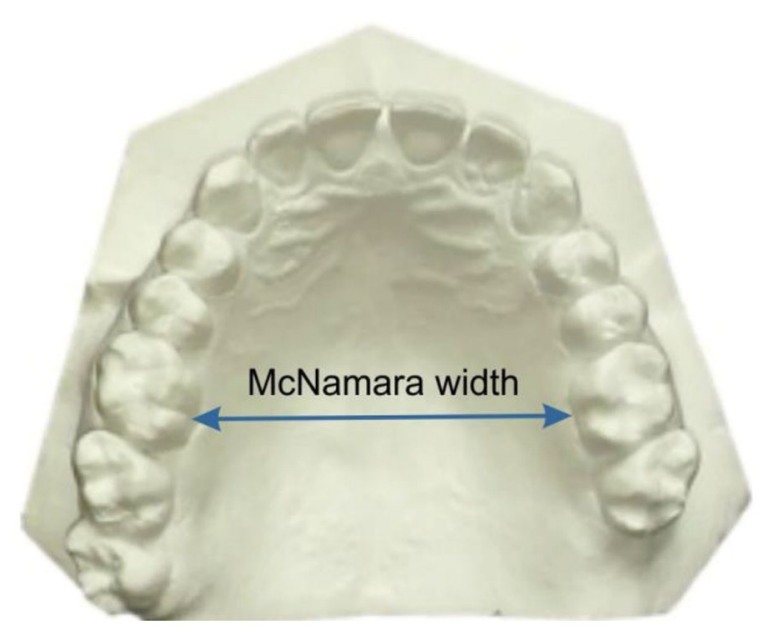

Figure 3. McNamara's transpalatal width. 
Table 1. Comparison of different arch widths in patients with diastema and without diastema

\begin{tabular}{|c|c|c|c|c|}
\hline \multirow[t]{2}{*}{ Arch width } & \multicolumn{2}{|c|}{ Mean [mm] } & \multirow[t]{2}{*}{ Test } & \multirow[t]{2}{*}{$\mathbf{P}$} \\
\hline & Patients with diastema & Patients without diastema & & \\
\hline Premolar upper & $37.98 \pm 2.87$ & $35.19 \pm 3.57$ & U Mann-Whitney & $<0.0001$ \\
\hline Premolar lower & $37.31 \pm 2.75$ & $35.67 \pm 2.97$ & U Mann-Whitney & $=0.0003$ \\
\hline Molar upper & $48.62 \pm 2.68$ & $45.38 \pm 2.75$ & Student t-test & $<0.0001$ \\
\hline Molar lower & $49.43 \pm 2.80$ & $46.91 \pm 3.23$ & Student t-test & $<0.0001$ \\
\hline
\end{tabular}

Table 2. Differences in transpalatal widths between the study and control groups

\begin{tabular}{lcccc}
\hline Group & \multicolumn{3}{c}{ Transpalatal width [mm] } & \multirow{2}{*}{$\chi^{2}$ test } \\
\cline { 2 - 4 } & $<\mathbf{3 6}$ & $\mathbf{3 6 - 3 8}$ & $\mathbf{3 8}$ & $\chi^{2}=27.43 ;$ \\
\hline Patients with diastema & $10(20.0 \%)$ & $27(52.0 \%)$ & $15(28.0 \%)$ & $\mathrm{p}<0.0001$ \\
Patients without diastema & $36(72.0 \%)$ & $8(16.0 \%)$ & $6(12.0 \%)$ & \\
\hline
\end{tabular}

group). Patients with severe malocclusion, craniofacial diseases, hypodontia and microdontia of teeth and patients with periodontal disease were excluded.

The following measurements were made:

1. Premolar upper arch width in central fossa of first premolars (Pont's point).

2. Molar upper arch width in mesial fossa of first molars (Pont's point).

3. Premolar lower arch width in contact points between the first and the second premolars (Pont's point).

4. Molar lower arch width in the second buccal cusp of the first molar (distal buccal cusp of 4-cusps molars or middle buccal cusp of 5-cusps molars) (Pont's point).

5. The transpalatal width according to McNamara between the first upper molars.

6. The width of diastema in study group between upper central incisors.

\section{Statistical analysis}

For the measurements, digital calliper with accuracy to $0.01 \mathrm{~mm}$ was used. Statistical analyses were performed using the Statistica 10.0 PL software (StatSoft Poland, Krakow). Significance of the differences was assessed using the nonparametric Mann-Whitney $\mathrm{U}$ test and parametric Student t-tests. The $\mathrm{p}$-values of the test statistics lower than 0.05 (two-sided) were considered significant.

\section{RESULTS}

Analysis of results showed differences between two groups. Patients with diastema had significantly $(p<0.05)$ wider dental arches then patients without diastema. Mean premolars and molars widths for upper and lower dental arches and statistics tests are shown in Table 1.

Mean premolar upper arch width was $37.98 \pm$ $\pm 2.87 \mathrm{~mm}$ in the patient group and $35.19 \pm 3.57 \mathrm{~mm}$ in the control group. Mean premolar lower arch width was $37.31 \pm 2.75 \mathrm{~mm}$ in the diastema group and $35.67 \pm 2.97 \mathrm{~mm}$ in the control group. Mean molar upper arch width was $48.62 \pm 2.68 \mathrm{~mm}$ in the patient group and $45.38 \pm 2.75 \mathrm{~mm}$ in the control group. Mean molar lower arch width was $49.43 \pm 2.80 \mathrm{~mm}$ for the diastema group and $46.91 \pm 3.23 \mathrm{~mm}$ for the group without diastema. All of the above mentioned parameters showed significant difference between the control and the patient groups $(p<0.05)$.

The differences between groups in McNamara transpalatal widths are shown in Table 2. Patients with diastema in 52\% had normal (36-38 $\mathrm{mm}$ ) transpalatal widths or $>38 \mathrm{~mm}$ in $28 \%$. In the control group transpalatal widths $<36 \mathrm{~mm}$ were dominant (72\%).

The analysis of diastema widths and McNamara transpalatal widths showed that there was not statistically significant correlation (Table 3).

\section{DISCUSSION}

The width of dental arches is changing during growth and dental development $[1,11]$. The results show that diastema patients have wider dental arches then patients without diastema. McNamara widths results were comparable to upper molar arch widths in Pont's points. Moreover upper molar arch widths 
Table 3. Correlation between width of diastema and transpalatal widths

\begin{tabular}{lcccc}
\hline Diastema width & \multicolumn{3}{c}{ Transpalatal width [mm] } & \multirow{2}{*}{$\chi^{2}$ test } \\
\cline { 2 - 4 } & $<\mathbf{3 6}$ & $\mathbf{3 6 - 3 8}$ & $\mathbf{3 6}$ & \\
\hline$\leq 2$ & $6(25.0 \%)$ & $9(37.5 \%)$ & $9(37.5 \%)$ & $\chi^{2}=3.93 ;$ \\
$>2$ & $5(17.9 \%)$ & $18(64.2 \%)$ & $5(17.9 \%)$ & $\mathrm{p}=0.1401$ \\
All & $11(21.2 \%)$ & $27(51.9 \%)$ & $14(26.9 \%)$ & - \\
\hline
\end{tabular}

as well premolar upper and lower widths were significantly larger in diastema group. This means that patients with diastema had dento-alveolar discrepancy that has been described in many papers and it is one of the causes of diastema $[4,9,12,20]$.

Comparison of the authors' own results with some other studies showed that diastema patients had normal widths of dental arches. The results from Kuwait of Rastegar-Lari's et al. [23] investigation concerning the width of dental arches in patients with ideal occlusion were similar to upper premolar and molar widths of diastema group. Mean upper premolar widths in Rastegar-Lari's investigation were $37.5 \pm 2.12 \mathrm{~mm}$, compared to the authors' own results of $37.98 \pm 2.87 \mathrm{~mm}$. Mean upper molar widths were $48.52 \pm 2.92 \mathrm{~mm}$ in Kuwait group and $48.62 \pm 2.68 \mathrm{~mm}$ in diastema group. That means that diastema groups of patients have similar width of upper dental arches to patients without malocclusion, with ideal occlusion.

An investigation in Chinese population with early permanent dentition showed that this population had wider dental arches than in Caucasians [17]. But comparison of results of dental arches widths in Chinese population and diastema group showed that the results of those two groups were similar for molar upper and lower dental arch widths and for upper premolar widths. But lower premolar width was wider in diastema patients. Those comparisons showed that maxillary midline diastema coexisted with wide dental arches.

A proper transpalatal arch width should be 36-38 $\mathrm{mm}$ for permanent dentition [18]. In the authors' own study the transpalatal arch widths were larger in diastema group of patients then in control group. In diastema group, proper transpalatal arch widths or larger than $38 \mathrm{~mm}$ were dominant. The group without diastema had narrow arches $<36 \mathrm{~mm}$. These results confirm dento-alveolar discrepancy described in literature with diastema patients with too wide arches compared with dental size $[4,9,12,20]$.
The control group with narrow transpalatal widths was similar to the investigated group by Krooks et al. [16] in Finland. He showed that the most popular malocclusion in adults was lateral cross bite. The most common cause of cross bite was narrowing of maxilla [18].

The study of Alvaran et al. [1] conducted among Colombians compared the width of the dental arches in various malocclusions. The results are as follows. Patients with class I malocclusion and teeth crowding more than $3 \mathrm{~mm}$ had smaller premolar width arches compared to patients with normal occlusion (Angle's class I and mild crowding $<3 \mathrm{~mm}$ ) and group with Angle's class II. These results confirmed the values obtained in the authors' own study in the control group. The premolar upper arch width in the control group was $35.19 \pm 3.57 \mathrm{~mm}$, and it was similar to patient with class I malocclusion in Alvaran et al.'s [1] study where the result was $35.6 \pm 1.8 \mathrm{~mm}$.

\section{CONCLUSIONS}

1. Patients with diastema had increased anterior and posterior width for both upper and lower arches.

2. The occurrence of normal or increased transpalatal width was characterised by $80 \%$ of patients with diastema.

3. Most patients without diastema had narrowing of the transpalatal width compared to the study group.

4. The width of the diastema did not correlate with the width of the palate.

\section{REFERENCES}

1. Alvaran N, Roldan SI, Buschang PH. Maxillary and mandibular arch widths of Colombians. Am J Orthod Dentofacial Orthop. 2009; 135(5): 649-656, doi: 10.1016/j. ajodo.2007.05.023, indexed in Pubmed: 19409348.

2. Attia Y. Midline diastemas: closure and stability. Angle Orthod. 1993; 63(3): 209-212, doi: 10.1043/0003-3219(1993) 063<0209:MDCAS>2.0.CO;2, indexed in Pubmed: 8214789.

3. Bednarz W, Sokołowski B. Kompleks śluzówkowo-dziąsłowy w wieku rozwojowym. E-Dentico. 2007; 1: 58-64. 
4. Bhattacharya P, Raju PS, Bajpai A. Prognosis v/s etiology: midline papilla reconstruction after closure of median diastema. Ann Essences Dent. 2011; 3: 37-40.

5. Bjork A, Krebs A, Solow B. A method for epidemiological registration of malocclusion. Acta Odontol Scand. 1964; 22: 27-41, indexed in Pubmed: 14158468.

6. Chu $\mathrm{CH}$, Zhang $\mathrm{CF}$, Jin LJ. Treating a maxillary midline diastema in adult patients: a general dentist's perspective. J Am Dent Assoc. 2011; 142(11): 1258-1264, indexed in Pubmed: 22041411.

7. Dalidjan M, Sampson W, Townsend G. Prediction of dental arch development: an assessment of Pont's Index in three human populations. Am J Orthod Dentofacial Orthop. 1995; 107(5): 465-475, indexed in Pubmed: 7733055.

8. Delli K, Livas C, Sculean A, et al. Facts and myths regarding the maxillary midline frenum and its treatment: a systematic review of the literature. Quintessence Int. 2013; 44(2): 177-187, doi: 10.3290/j.qi.a28925, indexed in Pubmed: 23444184.

9. Erdemir U, Yildiz E. Esthetic and Functional Management of Diastema: A Multidisciplinary Approach. Springer International Publishing 2015.

10. Gkantidis N, Kolokitha OE, Topouzelis N. Management of maxillary midline diastema with emphasis on etiology. J Clin Pediatr Dent. 2008; 32(4): 265-272, indexed in Pubmed: 18767455.

11. Hesby RM, Marshall SD, Dawson DV, et al. Transverse skeletal and dentoalveolar changes during growth. Am J Orthod Dentofacial Orthop. 2006; 130(6): 721-731, doi: 10.1016/j.ajodo.2005.03.026, indexed in Pubmed: 17169734

12. Huang WJ, Creath CJ. The midline diastema: a review of its etiology and treatment. Pediatr Dent. 1995; 17(3): 171-179, indexed in Pubmed: 7617490.

13. Joneja $\mathrm{P}$, Pal $\mathrm{V}$, Tiwari $\mathrm{M}$, et al. Factors to be considered in treatment of midline diastema. Int J Curr Pharm Res. 2013; 5: 1-3.

14. Kadouch DJM, Maas SM, Dubois L, et al. Surgical treatment of macroglossia in patients with Beckwith-Wiedemann syndrome: a 20-year experience and review of the literature. Int J Oral Maxillofac Surg. 2012; 41(3): 300-308, doi: 10.1016/j.ijom.2011.10.021, indexed in Pubmed: 22104000.

15. Korkut B, Yanikoglu F, Tagtekin D. Direct midline diastema closure with composite layering technique: a one-year follow-up. Case Rep Dent. 2016; 2016: 6810984, doi: 10.1155/2016/6810984, indexed in Pubmed: 26881147.

16. Krooks L, Pirttiniemi $P$, Kanavakis $G$, et al. Prevalence of malocclusion traits and orthodontic treatment in a Finn- ish adult population. Acta Odontol Scand. 2016; 74(5): 362-367, doi: 10.3109/00016357.2016.1151547, indexed in Pubmed: 26940248.

17. Ling JYK, Wong RWK. Dental arch widths of Southern Chinese. Angle Orthod. 2009; 79(1): 54-63, doi: 10.2319/092007452.1, indexed in Pubmed: 19123707.

18. McNamara JAJ, Brudon WL, Kokich VG. Orthodontics and Dentofacial Orthopedics. Needham Press INC, 2001.

19. Noureddine A, Fron Chabouis H, Parenton S, et al. Laypersons' esthetic perception of various computer-generated diastemas: a pilot study. J Prosthet Dent. 2014; 112(4): 914-920, doi: 10.1016/j.prosdent.2013.10.015, indexed in Pubmed: 24726592.

20. Oesterle $U$, Shellhart WC. Maxillary midline diastemas: a look at the causes. J Am Dent Assoc. 1999; 130(1): 85-94, indexed in Pubmed: 9919036.

21. Onyeaso $C$. Prevalence of malocclusion among adolescents in Ibadan, Nigeria. Am J Orthod Dentofac Orthop. 2004; 126(5): 604-607, doi: 10.1016/j.ajodo.2003.07.012.

22. Pont A. Der zahnindex in der orthodontie. Zahnearztliche Orthopeadie. 1909; 3: 306-321.

23. Rastegar-Lari T, Al-Azemi R, Thalib L, et al. Dental arch dimensions of adolescent Kuwaitis with untreated ideal occlusion: variation and validity of proposed expansion indexes. Am J Orthod Dentofacial Orthop. 2012; 142(5): 635-644, doi: 10.1016/j.ajodo.2012.05.018, indexed in Pubmed: 23116504.

24. Sękowska A, Chałas R. Diastema size and type of upper lip midline frenulum attachment. Folia Morphol. 2017; 76(3): 501-505, doi: 10.5603/FM.a2016.0079, indexed in Pubmed: 28026850.

25. Sękowska A, Dunin-Wilczyńska I, Chałas R. The size of anterior teeth in patients with gaps in the upper dental arch. Folia Morphol. 2015; 74(4): 493-496, doi: 10.5603/ FM.2015.0113, indexed in Pubmed: 26620511.

26. Shashua D, Artun J. Relapse after orthodontic correction of maxillary median diastema: a follow-up evaluation of consecutive cases. Angle Orthod. 1999; 69(3): 257-263, doi: 10.1043/0003-3219(1999)069<0257:RAOCOM > 2.3 .CO;2, indexed in Pubmed: 10371432.

27. Thilander $B$, Pena L, Infante $C$, et al. Prevalence of malocclusion and orthodontic treatment need in children and adolescents in Bogota, Colombia. An epidemiological study related to different stages of dental development. Eur J Orthod. 2001; 23(2): 153-167, indexed in Pubmed: 11398553.

28. Tyrologou S, Koch G, Kurol J. Location, complications and treatment of mesiodentes--a retrospective study in children. Swed Dent J. 2005; 29(1): 1-9, indexed in Pubmed: 15898358. 